\title{
THE EFFECT OF DEXTROSE 5\% IN WATER ON PERIPHERAL NERVE STIMULATION
}

Ban CH Tsui MD MSc FRCPC, Bruce Kropelin MD FRCPC

Department of Anesthesiology and Pain Medicine, University of Alberta, 8-120 Clinical

Sciences Building, Edmonton, Alberta, T6G 2G3

\section{INTRODUCTION}

When performing regional anesthesia a small volume of local anesthetic or normal saline abolishes a motor response induced by a low current $(0.5 \mathrm{~mA})$. In contrast, the injection of a non-conducting solution (dextrose $5 \%$ in water (D5W)) has been demonstrated to maintain a motor response in a porcine model by decreasing the conductive surface area and increasing the current density at the needle tip. ${ }^{1}$ This study examines the hypothesis that D5W will maintain an elicited motor response in a clinical setting.

\section{METHODS}

Following IRB approval, a prospective study was performed in 20 patients. Peripheral nerve blocks were performed in each patient using insulated needles. Each needle was primed with D5W. The needle was then advanced towards the target nerve until corresponding motor responses were observed using a current of $0.5 \mathrm{~mA}$ or less. Once the needle position was optimally placed, $1 \mathrm{~mL}$ of $\mathrm{D} 5 \mathrm{~W}$ was injected followed by a predetermined dose of local anesthetic. The effects of the injectates (D5W and local anesthetic) on the motor response were observed at all needle insertion sites.

\section{RESULTS}

A total of 29 single-shot peripheral blocks were performed in 20 patients. In all cases, the motor response was maintained (or augmented (96\%)) immediately after the injection of D5W. All motor responses diminished after the injection of local anesthetic (100\%). All blocks were considered clinically successful.

\begin{tabular}{|l|c|c|c|c|}
\hline \multicolumn{1}{|c|}{ Block } & $\begin{array}{c}\text { No. of } \\
\text { Patients }\end{array}$ & $\begin{array}{c}\text { Mean Threshold } \\
\text { Current (SD) }\end{array}$ & $\begin{array}{c}\text { Motor } \\
\text { response after } \\
\text { D5W }\end{array}$ & $\begin{array}{c}\text { Motor response } \\
\text { after local } \\
\text { anesthetic }\end{array}$ \\
\hline Supraclavicular & 3 & $0.29(0.16)$ & Present & Disappeared \\
\hline Interscalene & 5 & $0.42(0.06)$ & Present & Disappeared \\
\hline Sciatic & 11 & $0.36(0.11)$ & Present & Disappeared \\
\hline Femoral & 9 & $0.39(0.12)$ & Present & Disappeared \\
\hline Lumbar plexus & 1 & $0.4(\mathrm{~N} / \mathrm{A})$ & Present & Disappeared \\
\hline
\end{tabular}

\section{DISCUSSION}

The injection of a non-conducting solution (D5W) maintains or augments a motor response elicited by $0.5 \mathrm{~mA}$ or less. Utilizing an injection of D5W during single-shot peripheral nerve block may provide a uniform electrical field around the stimulating needle tip and a reproducible motor response.

\section{REFERENCE}

1. Reg Anesth Pain Med 29:189-93. 